\title{
English Corner: At the Crossroads?
}

\author{
David A. Kellaway
}

\begin{abstract}
This paper is based on an exploration into the phenomenon of English Corner. English Corner seems a curiously Chinese thing, rarely observed in its public format outside of the People's Republic of China. It is characterized by ad-hoc, relatively unorganized gatherings of people, who meet together on usually a weekly basis in a public place or inside the confines of a university, to practice speaking English. Attendance is voluntary and in its public format, free of charge. But in as much as it brings together groups of ESL (English as a Second Language) learners whose prima facie intention is to practice their oral English, English Corner can be seen as an informal learning strategy. The researcher's approach to understanding English Corner is ethnographic and observational, attending and observing meetings as they take place, interviewing randomly selected participants. The researcher is also interested in the future of English Corner as a public forum in the face of social media and online-moderated communication. Preliminary research outcomes suggest that people attend English Corner for a variety of reasons; certainly to practice oral English but also to expand social contacts, deal with work-related and personal problems, and not least to search for potential partners! While there appears to be no moderation of the group, research also suggests that there are some subjects which are typically avoided in English Corners (ie. "taboo" subjects).
\end{abstract}

Index Terms-Empowerment, English as a second language, foreign expert, group dynamics, informal learning.

\section{INTRODUCTION}

English is now the most widespread Second Language in the world. More importantly, it is the global language of business.

Since the 1978 "Reform and Opening Up" policies of former Communist Party chairman Deng Xiao Ping, the economy of the People's Republic of China has increasingly become modernized and export-oriented. Foreign companies - which frequently join with Chinese partners in Joint Ventures (JV) - are also increasingly part of the economic landscape.

For employees in these firms, proficiency in English is widely seen as a "passport" to higher-paying jobs in which they may need to have daily contact with colleagues overseas; moreover there is evidence that English ability is being increasingly used as a screening device by employers especially in service sector professions such as ICT, Finance and Hospitality, just to name a few.

Moreover, over 1.27 million Chinese students [1] now attend foreign educational institutions, for which proficiency in English is required not only for gaining a study visa, but for successful performance in academic studies in an English

Manuscript received October 15, 2012; revised January 15, 2013

D. A. Kellaway is with the British Council's English Language Teaching Development Project (ELTDP) in Sabah, Malaysia (email: david.kellaway@gmail.com). language environment. Students also face high-stakes tests; undergraduates who opt for Japan or the United States typically face the Test of English as a Foreign Language (TOEFL) while those heading for Australia or the UK require a minimum 6 (on a scale of 1 to 9) overall on the now ubiquitous International English Language Testing System (IELTS) test. (Postgraduates and those intending to migrate, require a rather challenging 7.5.)

Moreover, with the rapidly increasing wealth especially of the eastern seaboard manufacturing areas such as Shanghai and the Pearl River Delta, has come a greater interest in foreign manufactured goods, especially luxuries such as wine, motor vehicles, and clothing. Along with this has come a greater interest in foreign travel and awareness that English is the "lingua franca" of many foreign countries, and in cases such as India, the only common language.

As such there is a great interest in the teaching and learning of English.

\section{INFORMAL LEARNING}

Educational researchers have increasingly become interested in informal learning over the past fifty years, and in 1974 Coombs and Ahmad [2] proposed the classic distinction between formal, non-formal and informal education. Informal education, they said, was "unorganized, unsystematic and even unintentional at times, yet it accounts for the great bulk of any person's total lifetime learning including that of a highly 'schooled' person."

According to Feuer [3] "informal places of learning are settings outside the formal classroom where learning takes place experientially and often through social interaction ... a fun atmosphere, group activities, an absence of formal teachers, curriculum or grading scale."

Lave \& Wenger's concept of 'community of practice' and 'legitimate peripheral participation', though predicated on work communities, also applies to learner interaction in groups such as English Corner.

By emphasising the situational nature of learning [4] they pay attention to the construction of knowledge that results from the activities of particular practices that define the roles and practices of individuals and their communities. Informal learning at the workplace as a process inherently linked to identity, membership and interpersonal relations.

English Corner is an informal learning situation; one of many instances where Chinese people join together for shared learning purposes, or for public exercise/performance. Other examples include daily morning communal tai-chi, usually held in plazas adjacent to residential buildings, evening communal ballroom dancing, usually held in plazas near shopping centres, art galleries and museums, as well as the celebrations that surround yearly festivals such as the Spring Festival and the Mid-autumn Festival. 
While there is overwhelming agreement to the need for English, China has started from a relatively low base. Unlike her neighbors India, Vietnam, Hong Kong, South Korea and Japan, whose populations have experienced both the pleasure and pain of on-going contact with English-speakers - Hong Kong since the 1840s and Japan since the Meiji Restoration in 1867 and its occupation by Allied forces following the Second World War - mainland China has experienced no continuous or pervasive contact with large numbers of native English-speaking foreigners in the past century, since the fall of the Qing Dynasty (1911) which had exacerbated the Opium Wars decades earlier by announcing to a trade-hungry British Government that "there was nothing the British produced that could be of the slightest interest to the Qing court." How times have changed!

\section{ROOTS OF ENGLISH CORNER}

The roots of English Corner are uncertain, and there is little written about it, but it is possible variants of it were used by Christian missionaries as much as two hundred years ago, to develop the linguistic skills and cultural awareness of their congregations and future local church leaders. At some point, the English Corner has broken free of the church, and the public format - which is largely the topic of this research has now gathered critical mass to the point where it is self-perpetuating without any apparent organiser - religious, governmental, educational or otherwise - behind the scenes.

The religious influence is certainly still present however, notably in Chinese universities, where teacher/missionaries, especially of the Church of Jesus Christ of Latter Day Saints (Mormon) and Seventh Day Adventist churches accept "missions" of up to five years duration, to teach normally scheduled courses within university faculties, and to run English Corners open to all students on weekday evenings, where presumably discussions centre around religious themes. It's a curious situation, because technically there are very strict laws in China against religious proselytizing understandable, given events such as the Taiping Rebellion in the late $19^{\text {th }}$ and early $20^{\text {th }}$ century - nevertheless university administrators seem to turn a blind eye to the practice, perhaps on the basis that any English oral practice is better than no English oral practice and, anyway "better the devil you know..."

\section{RESEARCH QUESTION}

The overarching research question is "What is the role of the English Corner as a phenomenon of informal English learning in China?" Allied to this, what is the future of English Corner as a public forum in the face of the increasing prevalence of social media and online-moderated communication?

\section{Purpose OF The STUdY}

The purpose of the study is to better understand the phenomenon of the English Corner, and questions such as those listed below are helping to frame the research:

- Access to English Corner. Is it open to all?
- Where it is held? What criteria govern its location(s)?

- Do the same people attend week after week?

- Who does most of the talking? Do individual attendees dominate discussions? Do men tend to dominate? Do women?

- Do the participants form groups? Are they based on interest / age / sex?

- Do participants move freely from group to group?

- How long do people stay at the English Corner?

- What topics do people discuss? Are there taboo subjects? What topics are deemed acceptable?

- What is the nature of intra-group dynamics in the meetings?

- $\quad$ Are there relationships of power among the participants and if so, how are these expressed?

- What alternative informal methods do attendees employ to learn English?

- Why do participants privilege English Corner? What might they be doing were they not at the meeting?

- What kind of English do attendees wish to master? ie. for business, travel, pleasure?

- What role do "foreign experts" play in the English Corner? What are their motivations in attending?

- To what extent do attendees consider that English language is bound to its culture?

- What is the future of English Corner given the ubiquitous availability of online-moderated conversation through services such as Skype, QQ and Weibo.

\section{SignificANCE OF THE STUDY}

The study is significant as a way of attempting to understand the motivations of Chinese people who choose to attend English Corner. These motivations are most certainly educational in the case of students, but there appear to be others for different stakeholders, such as employed people who desire to widen their social contacts (and social capital) perhaps through meeting influential people. As stated earlier, Chinese people seem to be very comfortable with public gatherings with relatively informal structure and organization.

There being relatively few foreign teachers in China (compared to the number of English language students), many Chinese language learners express their frustration at the lack of available L1 speaking partners, but there is much evidence to suggest that for the purposes of acquiring proficiency in spoken English, a gathering such as English Corner, composed as it is of second language learners has significant advantages [5]. This is because peers share the frustrations of learning the language; moreover peerlearners:

- Are available.

- Tend not be judgmental.

- Language ability is about the same.

- Don't grade their language, or speak down to other learners.

\section{PRELIMINARY FINDINGS}

The researcher has observed English Corner meetings over the past four years and has interviewed twelve attendees thus far (the intention is to interview thirty, as well as survey 
questionnaires to as many attendees as possible. )

English Corner takes place outside the Guangzhou Public Library in Yuexiu District of Guangzhou each and every Sunday, commencing at approximately $11 \mathrm{am}$ and finishing when the last attendees leave at approximately $7 \mathrm{pm}$. Attendee numbers vary throughout the day, from 6 people in the early mornings through to a peak of about 50-60 people by mid-afternoon, and then decreasing again especially as dinner time/dusk approaches.

Attendees vary in age from about 7 years (accompanied by parents) to retired people in their 70's, with the average age appearing to be about 28. At the Guangzhou Library, there are as expected, a number of high school and university students but the largest group appears to be people whose work requires them to use English, especially people working in:

\section{- $\quad$ Trading Companies}

\section{- ICT/Service industries}

Notably, members of these groups are also among the most consistent attenders, with $60 \%$ claiming they attended every (or nearly every) week.

Respondents gave as reasons that they needed to talk with foreigners as part of their job, though as practice opportunities with native-speakers were limited, attendance at English Corner was the "next best thing." of the group of twelve interviewees, the following occupational split was noted:

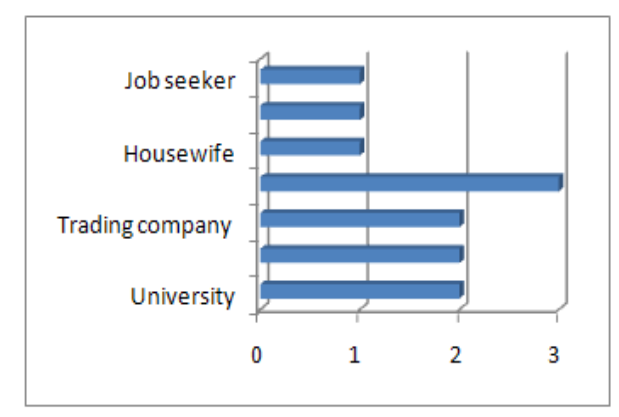

Fig. 1. Attendees by occupation

With respect to its location, historical reasons why the English Corner is held outside the Guangzhou Public Library are difficult to pin down. What is known is that it has operated from the same location - week in, week out - for more than ten years and there is no one in the group whoremembers it ever being held anywhere else.

It is held in a publicly accessible location in a courtyard about 50 meters from the entrance to the library and set about 100 meters back from a busy thoroughfare, Zhongshan 5 Road. A Metro station is located conveniently, as are a number of bus stops. A number of small family-owned restaurants are also located within easy walking distance.

The meetings take place beneath a very large and shady banyan tree, but there is no further protection from the weather (other than what the attendees bring along) and no seating, a situation commented on by one of the regular attendees, customer service representative Maria (26) who explained that "in summer it's really humid and hot and in winter it's freezing cold, but actually I will keep coming here because I like this activity myself but if it could be held in the library..."

English Corner appears to be open to all comers. Of the group of twelve initial interviews (11 and 18 November 2012), the researcher ascertained that four had not intended to come to English Corner at all, but had noticed the gathering of people in front of the Library as they entered the plaza and were curious what was happening. Three of the four expressed their intention to return to English Corner, though they were not certain how frequently.

Group membership seems to change markedly week by week, though there does seem to be a core of five or so very regular attendees. Marvin (40), an engineer who regularly deals with foreign clients, said he had attended the English Corner every week for the past four and a half years. "I have made a commitment to spending twenty hours a month on spoken English, and this is how I do it." Some, such as customer service representative Maria (26), attend multiple English Corners - also held on Tuesday and Friday nights at South China Normal University, on which Friday especially appears to attract a wide range of attendees as well as occasional foreign teaching staff from the university. There is also a Thursday night session at Zhongshan University.

Most respondents stated that men were generally the most represented (55\% on average) and talkative of the participants, but that groups tended to not to form on the basis of sex; rather on the basis of interest. However, the presence of a "foreign expert," especially a talkative one, tended to have drawing power and people would migrate to groups containing them.

Some respondents indicated that situations occasionally arose where an attendee would attempt to dominate discussions or become accusatory; though these were not regular attendees. When asked how they responded to such behavior (which is considered quite rude in Chinese society) the response seemed to be one of toleration - or simply moving to another group.

On any Sunday, the English Corner might be split into as many as 5 different groups in which different topics are being discussed. Movement between these groups is quite fluid, so it was felt to be easy to "escape" an unpleasant situation. Trainee pharmacist and regular attendee Arthur (24) expressed his discomfort with such attendees: “...some aggressive people here, Chinese people also, they just talktalk-talk-talk-talk - don't let other people to talk...one day, a Chinese guy kept asking a foreigner - I think he was from British - why are you here? Do you have Chinese teaching qualification? Are you here to make money?"

Approximately half the respondents claimed to be regular attenders, and those employed in jobs requiring English proficiency were heavily represented in this group. Most respondents indicated they expected to stay for a period of between one and four hours, with two hours being about average.

Some respondents expressed dissatisfaction with the range of topics being discussed; high school student Anna (17) who had discovered the group "by accident" on her way to borrow books from the library - felt the conversations were "not challenging enough" and doubted there was enough depth to maintain her interest, although she did mention that in her group, people had discussed their problems - such as performance at and attitude to school; boyfriends and the like. She felt more "comfortable" speaking to foreigners because "their mind are very interesting, especially the people that ... 
travels a lot, I admire them." University student Wing (22) said that sometimes the topics were "a bit silly really; they talk about how to build up your vocabulary, how to acquire some sort of an accent - and some very ordinary things: what's your job, where do you come from, where were you born and what do you enjoy?"

Software engineer Gavin (28) felt that many conversations revolved around self-introductions and didn't move much beyond that. At the same time, he expressed his discomfort with "political" topics: such as the relationship between Japan and China while noting that such topics did not arise frequently. Arthur (24) affirmed the frequency of politics and current-affairs in discussions he took part in: “... the Diaoyu islands; today the $18^{\text {th }}$ National Congress" although topics were not always so serious "sometimes they talk about fashionable things, heh heh, gossip, or sexy thing."

Wing (22) felt that speakers of English were generally "open minded people; of course some are more nationalistic than others but I think we are able to discuss all topics comfortably." Job-seeker Maureen (24) said she sometimes moved between groups: "if you didn't have any topics, you move around and see what people wear, what they are doing..." Maria (26) said that themes such as Christmas and Halloween and related activities were other frequent topics of conversation, moreover that people from English Corner had met in other locations (eg. Xiaogang Park) from time to time to celebrate them. She noted that conversations became quite personal at times and that some of her conversation partners had "a project which is helping a boy get rid of his single life and we hope that he will succeed but we are talking about his girlfriend and when they are going to get married..." Other respondents mentioned more mundane topics such as movies - both Chinese and foreign - as frequent topics.

Some respondents, such as Gavin (28) said that he sometimes met people from his workplace (HSBC) and hoped to meet people who might help him in his career, an attitude shared to some extent by Maria (26) who added a counseling dimension in saying that "most of the time outside of work I seldom talk about my job because this is my personal time... if you're already fed up with your job but now if you talk about it again but of course some of the girls are really confused and they're in the trouble of communication with their colleagues or their management, will talk about it and because we have different people from different companies and industry who can help solve the problem..."

Arthur (24) spoke of his desire to learn English in order to travel abroad so "I can see what is happening directly, not just what other people tell me" but also flagged its importance in the work setting where bosses also "look at your CET-6 or CET-4 as a condition to hire you." (College English Test (CET) is a standardised test of English proficiency, normally administered by Chinese universities: CET 4 is for non-English majors, CET 6 for English majors. There is anecdotal evidence that these are used by employers in China as a filter for job applications.)

Some respondents admitted that the search for a partner attracted them to English Corner. Gavin (28) said that "when I see a beautiful lady standing there, I will move over."

Wing (22) expressed the opinion that she did not expect the English Corner to be of much assistance to her career "I don't think you'll find too many high-powered managers here!" but enthused over one friend she had made through English Corner - an expert in ethnic music.

Some respondents felt they were benefiting but not as much as they had hoped. Even so, Anna (17), who was quite critical of the lack of depth in conversations, nevertheless expressed her intention to become a regular attender in order to avoid her boring school environment, to "breathe some fresh air, meet some new people and make my life become more interesting." Arthur (24) said he supported his oral English learning by attending weekly lectures at the American consulate.

With respect to online-mediated communication and its likely effect on the future of English Corner, most respondents said they used online communication tools such as QQ, Skype and Weibo, but that they tended to type rather than talk to their on-line partners. Gavin (28) spoke freely and critically of what he saw as government internet censorship, saying "the network is not stable because the Government is terrible." Wing (22) said she was aware of the tools and used Skype to talk to "old friends" though she found Weibo "trivial - I'm not interested in that, I find it distractive." Anna (17) said she had a few "foreign friends," one of whom she communicated with by QQ, but that she used email more than chatting. Maria (26) used the tools but never for English, but felt they would have broader influence over not just English Corner, but on the way people communicate generally: "...some influence on face-to-face communication...mobile phones set a border between people - it's not intentional but little by little, step by step, people don't communicate face to face anymore."

Marvin (40) described himself as an "old-fashioned learner," finding little of benefit on the internet in support of English learning, especially speaking.

Interestingly, two attendees -Wing and Anna - at the researcher's invitation in the following week participated in one of the monthly meetings of the Guangzhou Book Club, held at the New Page bookshop in Tianhe district. The meeting was conducted entirely in English and was essentially the discussion of an English novel. Both appeared comfortable and participated well.

Much remains to be completed in this research, which is considerably less than half completed. Foreign (native speaker) attendees also have perspectives on the English Corner, and while there are few regular attendees, their voices need also to be heard. Anecdotal evidence suggests that some foreigners attend in order to promote a school or a particular type of English learning device/software with which they are associated, while others (including the author) attended initially because they were new to the city and English Corner was an excellent repository of information about the city, for example "where can I get my shoes repaired?"

Moreover, no broad-based survey research has been conducted; the researcher is even now working on a survey instrument and deciding research populations.

Even so with research far from complete, English Corner appears not to be at a crossroads - there is little evidence that social media or online-moderated communication is replacing the need for face to face English practice, rather both are seen as necessary and complementary approaches. 


\section{REFERENCES}

[1] S. Chen. Chinese Overseas Students Hit Record High. [Online]. Available: http://www.bbc.co.uk/news/world-asia-pacific-13114577.

[2] P. Coombs and M. Ahmed, Attacking Rural Poverty, Johns Hopkins University Press: Baltimore, pp 8-12, 1993.

[3] A. Feuer, "School's out for the summer: A Cross Cultural Comparison of Second Language Learning in Informal Settings," Ph.D. dissertation, Department of Education, University of Maryland, MD, 2009.

[4] B. Morris, "Mentoring trainee teachers in the voluntary and community sector: a case study in initial teacher training," Ph.D. dissertation, Department of Education, Nottingham University, UK, 2010.

[5] X. Gao, "Forget Chinese-let's only think in English!' Chinese Netizens Debating the Best Ways to Learn English in China," Changing English, vol. 15 , no. 4, pp. 435-444, 2008.

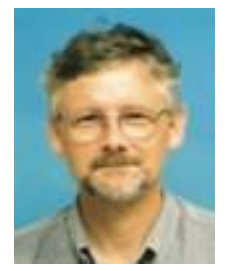

David Kellaway is currently studying for a Doctorate of Education (Ed D) at the University of Nottingham, researching informal methods of English learning among Chinese ESL learners. He has extensive experience as a primary school teacher in Australia, has worked as a trainer and documentation author in the Finance and ICT industries, and has spent the las nine years teaching Academic Writing and Seminar/ Discussion skills as university preparation courses in Guangzhou, China. He is also a respected wine columnist and restaurant reviewer. 